\title{
Outcome of Titanium Elastic Nails in Pediatric Femoral Fractures
}

Abdul Haque $^{1 *}$, Sheik Md. Abdullah Rafi ${ }^{2}$

${ }^{1}$ Associate Professor, Department of Orthopedic Surgery, Cumilla Medical College, Cumilla, Bangladesh

${ }^{2}$ Consultant, Cumilla Trauma Center, Cumilla, Bangladesh

DOI: $10.36347 /$ sjams.2020.v08i09.007

| Received: 30.08.2020 | Accepted: 07.09.2020 | Published: 09.09.2020

*Corresponding author: Abdul Haque

\section{Abstract}

Background: Femoral fractures are common fractures in paediatric age group. There are various methods to treat such cases. Titanium elastic nailing is one of them and an established and reliable method for treating these types of fractures. Ideal treatment of fractures in the age group of 5 to 14 years is still a matter of debate as no consensus has been achieved till now. Aim of the study: The aim of this study was to evaluate the outcome of using titanium elastic nails (TEN) in pediatric femoral fractures. Methods: This observational prospective study was conducted in Cumilla Trauma Center, Cumilla, Bangladesh during the period from January 2018 to July 2019 . A group of 50 children with femoral fractures selected to treat with titanium elastic nailing were finalized as the study population. All the information along with the outcomes of the participants were collected assessed and disseminated by several tables and charts of MS Office program. Results: In 20\%, 14\%, $4 \%$ and 2\% cases we found superficial infection, mal-union, deep infection and nail breakage as complication respectively. As the final outcome of this study we found, the results were excellent in 34 patients $(68 \%)$ successful in $12(24 \%)$ and poor in 4 patient $(8 \%)$ as per the scoring criteria for TEN by Flynn et al. Entry site irritation occurred in 3 patients limb lengthening $(<1.5 \mathrm{~cm})$ was found in 3 cases both clinically and radiologically, which was clinically insignificant nail removal at 5 th month, due to wound breakdown at entry sets in one case. Results were better for children in less than 10 years of age. Conclusion: Titanium elastic nailing is the method of choice for the simple pediatrics femoral fractures, as it is minimally invasive and shows good functional and cosmetic results. Surgical technique of this procedure is simple and reproducible. It allows short hospital stay and quick recovery from pain and it is cast-free.

Keywords: Titanium elastic nails, Outcome, Pediatric, Femoral fractures.

Copyright @ 2020: This is an open-access article distributed under the terms of the Creative Commons Attribution license which permits unrestricted use, distribution, and reproduction in any medium for non-commercial use (NonCommercial, or CC-BY-NC) provided the original author and source are credited.

\section{INTRODUCTION}

Femoral fractures are common fractures in paediatric age group. There are various methods to treat such cases. Titanium elastic nailing is one of them and an established and reliable method for treating these types of fractures. Ideal treatment of fractures in the age group of 5 to 14 years is still a matter of debate as no consensus has been achieved till now. The aim of this study was to evaluate the outcome of using titanium elastic nails (TEN) in pediatric femoral fractures. Fractures of femur are the most common but incapacitating fractures in children. They account for approximately $1.6 \%$ of all bony injuries in children [1]. In fact, femoral fracture is the most common major paediatric orthopaedic injury requiring hospitalization. The treatment has traditionally been age-related, influenced by the location and type of the fracture and associated injuries [2]. Because of rapid healing and spontaneous correction of angulation most of the femoral shaft fractures in children younger than six years of age can be treated conservatively [3]. The problem arises when operative stabilization becomes necessary due to failure to obtain or maintain an acceptable reduction of the fracture by conservative methods. The best treatment between 6 and 16 years of age is a matter of debate. Since the last two decades, there has been a growing tendency towards a more operative approach in patents over six years of age [2]. The previous methods of operative stabilization of paediatric femoral shaft fractures included external fixation, compression plating and rigid intramedullary nailing [4]. Ender's nails and titanium elastic nails are the two types of flexible intramedullary nails used over the years [5]. Titanium Elastic Nailing, which is variously known as Elastic Stable Intramedullary Nailing, has become the choice of stabilization in pediatric long bone fractures, particularly the femoral shaft fractures. The determination of ideal treatment of femoral shaft fracture in each child depends upon age of the child, the location and type of the fractures, the family environment, the knowledge and the ability and 
preferences of the surgeon [6], and to the lesser degree the financial implications. Below the age of 5 years, it is still a consensus to treat the child with fracture shaft femur conservatively as rapid healing and spontaneous correction of angulation takes place below this age group [7, 8]. Near the end of skeletal maturity angular deformity is not correctable by growth, so, accurate reduction is necessary [9]. The availability of locked intramedullary nail has developed the treatment of femoral shaft fractures in skeletally matured children well established. However, the best treatment between 5 and 14 years of age is a matter of debate [10]. We know that the biomechanical properties of titanium are often considered to be superior to those of stainless steel for intramedullary fracture fixation and in vitro mechanical studies have demonstrated equal or superior fixation of pediatric femoral fractures with use of titanium elastic nails as compared with stainless steel elastic nails [11]. The perceived advantage of this technique includes the early union due to repeated micro motion at fracture site, respect for early mobilization, early weight bearing, scar acceptance, easy implant removal and high patient satisfaction rate. We found many positive features of this technic.

\section{OBJECTIVES}

\section{General Objective}

- To evaluate the outcome of using titanium elastic nails (TEN) in pediatric femoral fractures.

\section{Specific Objective}

- To assess the complication of using titanium elastic nails in pediatric femoral fractures.

\section{Methodology \& Materials}

This observational prospective study was conducted in Cumilla Trauma Center, Cumilla, Bangladesh during the period from January 2018 to July 2019. A group of 50 children with femoral fractures (Winquist and Hansen Type I and II) selected to treat with titanium elastic nailing were finalized as the study population. Exclusion criteria were segmental, Winquist types III and IV comminuted fractures, previously diagnosed neuromuscular disease (Cerebral palsy), metabolic bone disorders (Osteomalacia), or pathological fractures, history of previous fracture or deformity in either limbs. The proper informed consent were taken in favor of all the participants. After a linear incision of about $2 \mathrm{~cm}$, opening the fascia, and splitting the muscle fibers, a hole was opened in the distal femoral metaphysis about $2 \mathrm{~cm}$ proximal to distal femoral physis plate with a curved owl and enlarged. Then, each prebent titanium elastic nail was placed in retrograde through the distal part of the femur. Each nail was about $40 \%$ of the canal diameter at the narrowest site of the femoral shaft. Those cases where close reduction could not be achieved, open reduction were done through $2.5 \mathrm{~cm}$ antero lateral incision at the level of fracture. Nail was cut short to bury under the soft tissue. Wound was closed with sutures. Compression dressing was applied. All the patients received second-generation cephalosporin as prophylaxis, which was initiated just before the operation and continued 72 hours postoperatively. Knee bending exercises was started post operatively as pain tolerated. Patients were discharged after $3^{\text {rd }}$ postoperative days with non-weight bearing crutch walking and followed up in outpatient department. Follow-up visits were made at two weeks when sutures were removed, six weeks when wound infection and progress of union was observed in $\mathrm{x}$ ray. Besides these, patients were allowed to bear weight as tolerated. Then the patients were followed up every fortnight to see progress of union. Nails were removed when union was achieved radiologically as well as clinically. Radiographs were reviewed for evidence of healing, defined as bridged femoral cortices (three or four of four cortices) on anteroposterior and lateral radiographs. Clinical union was considered when patient can walk comfortably without support. Limb alignment and limb length discrepancy were assessed immediate post operatively and at the final follow up when nails were removed. Measurements of angulations in the sagittal and coronal planes were done on antero posterior and lateral radiographs that were made at the first postoperative day and at the time of removal of the nail. Limb length discrepancy was also measured in comparison to normal limb. Range of knee motion, incision and skin infections were also assessed at each visit. After six months post operatively all parents were contacted by phone to find out any possible complications. The complications were classified as major or minor. Major complications were defined as conditions leading to unscheduled nail removal or operative treatment, including deep infection, implant irritation, or pain and nail breakage and mal-union and nonunion. All the information along with the outcomes of the participants were collected assessed and disseminated by several tables and charts of MS Office program.

\section{RESUlTS}

In this study finally 50 subjects were as study population. Among the 27 were male which was $54 \%$ and 23 were female which was $46 \%$. So male were dominating in number. In age distribution of the study we found, the highest 28 patients were from 11 to 15 years' age group whereas 22 were from 5-10 years' age group. In our study we found, in the highest number of cases the mechanism of injury was RTA (Road traffic accident) and it was $52 \%$. Then in $42 \%$ it was 'fall from height' and in $6 \%$ vcases it was 'sport injury'. On the other hand, in this study we found, in the highest number of cases the side of injury was 'right' and it was $78 \%$ whereas in $22 \%$ cases it was 'left'. The median duration of surgery was $74 \mathrm{~min}$ (60-min-110min) whereas the mean hospital stay was 10 days (7-20 days). All the patients were available for evaluation after a period of 6 months follow up. Radiological 
union was achieved in all cases in a meantime of 8 weeks (6week -12 weeks). Full weight bearing was achieved in a meantime of 8 weeks (6 weeks -12 weeks). In this treatment technic we had noticed some complications also. In $20 \%, 14 \%, 4 \%$ and $2 \%$ cases we found superficial infection, mal-union, deep infection and nail breakage as complication respectively. As the final outcome of this study we found, the results were excellent in 34 patients $(68 \%)$ successful in $12(24 \%)$ and poor in 4 patient $(8 \%)$ as per the scoring criteria for TEN by Flynn et al., Entry site irritation occurred in 3 patients limb lengthening $(<1.5 \mathrm{~cm})$ was found in 3 cases both clinically and radiologically, which was clinically insignificant nail removal at 5 th month, due to wound breakdown at entry sets in one case. Results were better for children in less than 10 years of age.

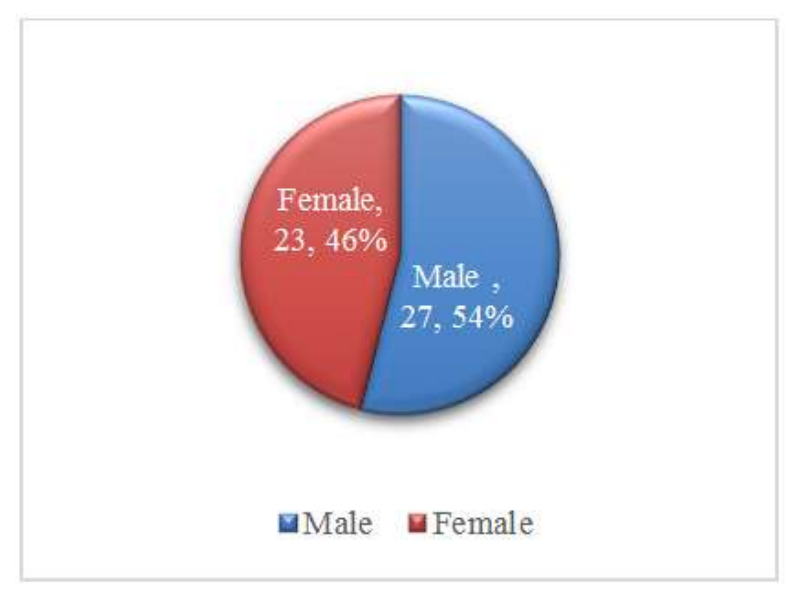

Fig-1: Gender distribution of participants $(\mathrm{N}=50)$

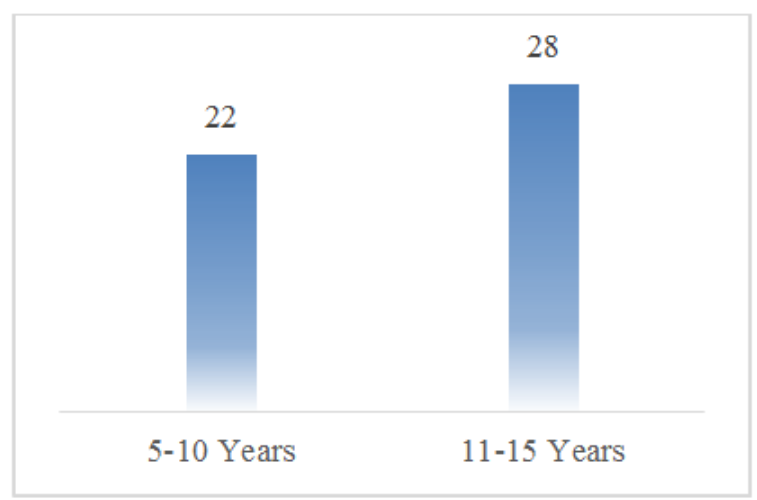

Fig-2: Age distribution of participants $(\mathrm{N}=50)$

Table-1: Mechanism of injury among participants (N=50)

\begin{tabular}{|l|l|l|}
\hline Mechanism & n & \% \\
\hline Fall from height & 21 & $42 \%$ \\
\hline RTA & 26 & $52 \%$ \\
\hline Sport injury & 3 & $6 \%$ \\
\hline Total & 50 & $100 \%$ \\
\hline
\end{tabular}

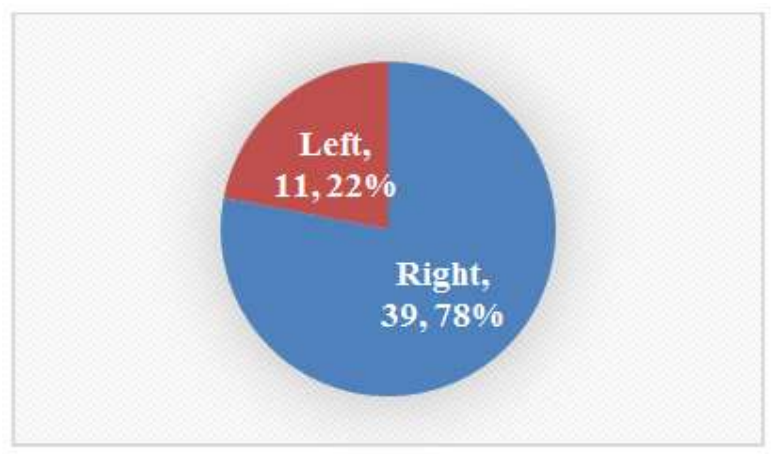

Fig-3: Side of injury among participants $(\mathrm{N}=50)$

Table-2: Complications among participants $(\mathbf{N}=50)$

\begin{tabular}{|l|l|l|}
\hline Complications & $\mathrm{n}$ & $\%$ \\
\hline Superficial infection & 10 & $20 \%$ \\
\hline Mal-union & 7 & $14 \%$ \\
\hline Deep infection & 2 & $4 \%$ \\
\hline Nail breakage & 1 & $2 \%$ \\
\hline
\end{tabular}

Table-3: Final outcomes among participants $(\mathbf{N}=50)$

\begin{tabular}{|l|l|l|}
\hline Clinical results & n & \% \\
\hline Excellent & 34 & $68 \%$ \\
\hline Successful & 12 & $24 \%$ \\
\hline Poor & 4 & $8 \%$ \\
\hline Total & 50 & $100 \%$ \\
\hline
\end{tabular}

\section{DisCUSSION}

In fact, titanium elastic nail (TEN) is an elastic stable intramedullary nail. It works on the principle of symmetric bracing action of two elastic nails having same modulus of elasticity; which causes three point fixation \& gives rotational, axial, transitional as well as bending stability by counteracting the distraction and compression forces working on diaphysis of femur. TD Bhattacharya et al., said that, Titanium Elastic Nail (TEN) does not provide adequate stability in comminuted, long oblique or spiral fractures or even if it is contemplated post-operative immobilization is essential [12]. Transverse, short oblique, short spiral with minimum comminution are best indications. There are no enough comparative studies regarding efficacy between Enders nail [3], Rush nail and TEN exist. Risk of complication of operative procedure is always there [13]. Studies have found that TEN is advantageous over hip spica in femoral shaft fracture in children as a treatment method [14]. Advantages of TEN are reduced hospitalization [15] and early mobilization. The result of Femoral Intramedullary Nail done in preschool children will achieve recovery milestones much faster than those treated with traction and spica cast study of 72 cases [16]. TEN is indicated in all femoral diaphyseal fractures of children above 6 years till physeal closure [17]. In our study TEN was found asa good and cost effective option considering less hospital stay and early return to walk. Even though drawbacks of this method over other methods of treatment are of cause the issue of just narration [18]. Important advantages are that the periosteum is not disturbed and 
being a closed procedure there is no disturbance of fracture hematoma so chance of infection is less. TEN as a retrograde technique of nailing have less chances of AVN of femoral head [19]. In fact, pediatric femoral shaft fractures are conventionally treated by either primary hip spica or skin traction followed by hip spica. Fractures readily unite with some amount of overlapping and angulations which is believed to get corrected by remodeling potentiality in children [20]. This treatment requires prolonged hospitalization or immobility which has raised awareness of the possible social, economic, educational, and emotional burden of prolonged immobilization [21]. After publication of good outcomes by the Nancy group in the early 1980s, Elastic Stable Intramedullary Nailing (ESIN) has become a well- accepted method of surgical treatment of long bone fractures in children and adolescents [22]. Compared to plating, flexible intramedullary nailing of the femoral shaft fractures in patients provides better results [23]. There are many reasons for this acceptance including absence of postoperative casting in most cases, primary bone union without growth plate injury, rapid recovery of joint motion and return to physical activities, minimally invasive surgery allowing small and aesthetic scars, low infection rate, and shortened hospital stays [24]. In our series, there was more male as compared to female child which can be explained by the fact that male children are physically more active so get more injuries. In this study finally 50 subjects were as study population. Among the 27 were male which was $54 \%$ and 23 were female which was $46 \%$. So male were dominating in number. Average union time was 12.8 week which is in comparison with the other series $[25,26]$. In this current study in $20 \%, 14 \%, 4 \%$ and $2 \%$ cases we found superficial infection, mal-union, deep infection and nail breakage as complication respectively. We encountered $5(12.5 \%)$ cases of malunion but this mal-union did not present any clinical and functional disability. Our rate of mal-union is less that other series [27]. Li et al., provided biomechanical evidence that patients weighing more than 40 to $45 \mathrm{~kg}$ who undergo stabilization of a transverse midshaft femur fracture with ESIN are at risk for loss of reduction in the sagittal and coronal planes [28]. We believe that remodeling potentiality in children will rectify angulation over period of time as shown in series of Flyn et al., where 20 degree angulation was remodeled to 7 degrees over a period of one year [29]. In our series we encountered10 case so superficial infection which resolves after removal of nail. This problem occurred in our initial cases where the nail was left long. This was protruding under the skin and cause infection. In later cases we used to cut the nail only one centimeter out of bone. Although in literature many complications including osteomyelitis, re-fracture, asymptomatic proximal nail migration, delayed healing or nonunion were described, in our series we did not encounter such complications [30].

\section{Limitations of THE STUdy}

This was a single centered study with a small sized sample. So the findings of this study may not reflect the exact scenario of the whole country.

\section{CONCLUSION AND RECOMMENDATIONS}

Titanium elastic nailing is the method of choice for the simple pediatrics femoral fractures, as it is minimally invasive and shows good functional and cosmetic results. Surgical technique of this procedure is simple and reproducible. It allows short hospital stay and quick recovery from pain and it is cast-free.For getting more specific findings we would like to recommend for conducting more studies regarding the same issue with larger sized sample.

\section{REFERENCES}

1. Kasser JR, Beaty JH. Femoral shaft fractures. In: Beaty JH, Kasser JR, ed. Rockwood and Wilkins fractures in children. 6th ed. New York: Lippincott Williams and Wilkins, 2006: 893.

2. Flynn JM, Skaggs DL, Sponseller PD, Ganley TJ, Kay RM, Kellie Leitch KK. The operative management of pediatric fractures of the lower extremity. J Bone Joint Surg Am. 2002; 84:2288300 .

3. Saikia KC, Bhuyan SK, Bhattacharya TD, Saikia SP. Titanium elastic nailing in femoral diaphyseal fractures of children in 6-16 years of age. Indian Journal of Orthopaedics, 2007 Oct-Dec; 41(4):381-385.

4. Metaizeau JP. Stable elastic nailing for fractures of the femur in children. J Bone Joint Surg Br. 2004; 86:954-7.

5. Barry M, Paterson JM. A flexible intramedullary nails for fractures in children. J Bone Joint Surg Br. 2004 Sep; 86(7):947-53.

6. Narayanan UG, Hyman JE, Wainwright AM, Rang M, Alman BA. Complications of elastic stable intramedullary nail fixation of pediatric femoral fractures and How to avoid them. J Pediatr Orthop. 2004; 24: 363-9.

7. Buckley SL. Current trends in the treatment of femoral shaft fractures in children and adolescents. Clin Orthop Relat Res. 1997; 338: 60-73.

8. Gwyn DT, Olney BW, Dart BR, Czuwala PJ. Rotational control of various pediatric femur fractures stabilized with Titanium Elastic Nails. J Pediatr Orthop. 2004; 24: 172-7.

9. Metaizeau JP. Stable elastic nailing for fractures of the femur in children. J Bone Joint Surg Br. 2004; 86: 954-7.

10. Flynn JM, Luedtke LM, Ganley TJ, Dawson J, Davidson RS, Dormans JP, Ecker ML, Gregg JR, Horn BD, Drummond DS. Comparison of titanium elastic nails with traction and a spica cast to treat 
femoral fractures in children. JBJS. 2004 Apr 1;86(4):770-7.

11. Eric J. Wall, Viral Jain, VagminVora, Charles T. Mehlman, Alvin H. Crawford. Complications of Titanium and Stainless Steel Elastic Nail Fixation of Pediatric Femoral Fractures the Journal of Bone \& Joint Surgery. 2008; 90: 1305-1313.

12. K.C. Saikia, S K Bhuyan, T.D. Bhattacharya, Titanium elastic nailing in femoral diaphyseal fractures of children in 6-16 years of age. IJO. 2007; 41(4):381-385.

13. Goodship AE. The influence of induced micromovement upon the healing of experimental tibia fractures. JBJS. 1985; 67B(4):650-655.

14. Buechsenschuetz KE, Mehlman CT, Shaw KJ, Crawford AH, Immerman EB. Femoral shaft fractures in children: Traction \& cast versus elastic stable intramedullary nailing. J Trauma. 2002: (53):914-21.

15. Herndon WA, Mahnken RF, Yngve DA, Sullivan JA. Management of femoral shaft fractures in adolescents. J Peditr Orthop. 1989; 9:29-32.

16. Bopst L, Reinberg O, Lutz N. Femur fracture in preschool children: experience with flexible intramedullary nailing in 72 children. J Pediatr Orthop, 2007: (27):299-303.

17. Lascombes P, Haumont T, Journeau P. Use and abuse of flexible intramedullary nailing in children and adolescents, J Pediaric Orthop, 2006 (26):82734.

18. Luhmann SJ, Schootman M, Schoenecker PL, Dobbs MB, Gordon JE. Complications of titanium elastic nails for pediartric femoral shaft fractures. J Pediatr Orthop. 2003 Jul-Aug; 23(4): 443-447.

19. Vierhout BP, Sleeboom C, Aronson DC, VanWalsum AD, Zilp G., Heij HA, Long term outcome of elastic stable intramedullary fixation of femoral fractures in children. Eur J Pediatr Surg, 2006 (16): 432-437.

20. Salem KH, Lindemann I, Keppler P. Flexible intramedullary nailing in pediatric lower limb fractures. J Pediatr Orthop. 2006 Jul-Aug; 26(4):505-9.

21. Wright JG. The treatment of femoral shaft fractures in children: a systematic overview and critical appraisal of the literature. Can J Surg. 2000; 43:180-9.

22. Me'taizeau JP. L'oste'osynthe'se de l'enfant: techniques et indications. Rev Chir Orthop. 1983; 69:495-511.

23. Caglar O, Aksoy MC, Yazici M, Surat A. Comparison of compression plate and flexible intramedullary nail fixation in pediatric femoral shaft fractures. J Pediatr Orthop Br. 2006; 15:210 14.

24. Lascombes P, Haumont T, Journeau P. Use and abuse of flexible intramedullary nailing in children and adolescents. J Pediatr Orthop. 2006; 26:827834.

25. Cramer KE1, Tornetta P 3rd, Spero CR, Alter S, Miraliakbar $\mathrm{H}$, Teefey J: Ender rod fixation for femoral shaft fractures in children. Clinorthop. 2000 Jul; (376):119-23.

26. Flyn JM, Schwend RM. Managememt of pediatric femoral shaft Fractures. J am acadorthop surg. Sep-oct 2004; 12(5):347-59.

27. Eric J. Wall, Viral Jain, VagminVora, Charles T, Mehlman and AlvinH. Crawford Complications of Titanium and Stainless Steel Elastic Nail Fixation of Pediatric femoral fractures. J Bone Joint Surg Am. 2008; 90:1305-1313.

28. Li Y, Stabile KJ, Shilt JS. Biomechanical analysis of titanium elastic nail fixation in a pediatric femur fracture model. J Pediatr Orthop. 2008; 28:874878.

29. Kasser JR. Femoral shaft fractures. In: Rockwood CA Jr, Wilkins KE, Beaty JE. Fractures in children. Lippincott, Philadelphia, 1996.

30. Wall EJ, Jain V, Vora V, Mehlman CT, Crawford AH. Complications of titanium and stainless steel elastic nail fixation of pediatric femoral fractures. JBJS. 2008 Jun 1;90(6):1305-13. 